\title{
Um Atlântico Luso-Afro-Brasileiro. Ecos de Gilberto Freyre em Augusto de Castro e Norton de Matos
}

\author{
A Luso-Afro-Brazilian Atlantic. Echoes of Gilberto Freyre in Augusto de Castro and \\ Norton de Matos
}

\section{Clara Isabel Serrano}

Doutora em Altos Estudos Contemporâneos Investigadora integrada do Centro de Estudos Interdisciplinares do Século XX, CEIS20, da Universidade de Coimbra

claraisabelmeloserra@gmail.com

\author{
Sérgio Neto \\ Doutorando em Altos Estudos Contemporâneos \\ Investigador integrada do Centro de Estudos Interdisciplinares do \\ Século XX, CEIS20, da Universidade de Coimbra \\ sgdneto@gmail.com
}

Resumo: A última década continua a revelar que o luso-tropicalismo e a crença numa excepcionalidade portuguesa, no que respeita ao racismo, se encontra presente na sociedade portuguesa. Na verdade, a teoria de Gilberto Freyre foi cooptada pelo Estado Novo salazarista, como estandarte ideológico de defesa contra os movimentos anticoloniais e as pressões das Nações Unidas para a independência das suas colónias. O presente artigo pretende testar esta situação, tendo por base os estudos mais recentes e escolhendo dois vultos intelectuais da primeira metade do século XX (um partidário do regime e um opositor).

Palavras-chave: $\quad$ Portugal/Brasil/África; Luso-Tropicalismo; Colonialismo.
Abstract: In Portugal, in the last ten years, it's possible to apprehend that the luso-tropicalism prevails, as far as racism concerns. The theory of Gilberto Freyre became a flag to the New State Regime (Estado Novo) against the anticolonial movements and the pressure of the United Nations for the colonies independence. This article intends to discuss the latest studies on the subject and to analyze two intellectuals from the first half of the 20th Century. A follower of the regime (Augusto de Castro) and a member of the Opposition (José Norton de Matos).

Keywords: Portugal/Brazil/Africa; LusoTropicalism; Colonialism. 
Mercê de uma investigação a um tempo académica (ARAÚJO \& MAESO, 2016) e jornalística (HENRIQUES \& BATISTA, 2016), fundada numa realidade complexa e cuja desconstrução urge levar a cabo, os últimos anos têm desvelado que a sociedade portuguesa continua a manter uma relação ambígua e de difícil catalogação, no que concerne ao seu passado colonial. Na verdade, a questão já havia sido diagnosticada pelo filósofo Eduardo Lourenço, ainda antes da descolonização lusa do império em África, quando postulara que mergulhado numa guerra que se perpetuava (1961-1974), acusado na Organização das Nações Unidas (ONU) de colonialista e cada vez mais solitário na comunidade internacional, o país teimava em escamotear com "fracos" argumentos a questão principal. E esta teria a sua génese numa "hipertrofia" do ethos nacional, ao engendrar-se a convicção de que Portugal seria menos sensível ao racismo do que qualquer outra potência imperial, pois que as colónias não passariam, afinal, de prolongamentos territoriais e humanos da metrópole, cuja separação (independência) era assimilada a uma metáfora cara ao nacionalismo: justamente a amputação (LOURENÇO, 1976: 34).

Tal crença, cujas primícias remontam às Luzes pombalinas setecentistas que ditaram o fim da escravatura (ainda que somente em território metropolitano), ou talvez em última análise, a elementos colhidos nas pretensões redentoras do Catolicismo e a episódios ditos exemplares do expansionismo, continua, segundo alguns autores, a manter-se no imaginário português, através de uma longa linha discursiva, enriquecida por muitos avatares, que percorreu diversos regimes políticos: Monarquia Constitucional (1820-1910), Primeira República (1910-1926), Ditadura Militar (1926-1933), Estado Novo (1933-1974) e a actual Terceira República (1974-....). Ora, foi com o Estado Novo, com a sua suposta "vocação" colonial, que a ideologia ultramarina cristalizou os seus princípios maiores, incorporando outros ou despindo-os de aspectos susceptíveis de se tornarem polémicos. Foi o caso da doutrina luso-tropical, de Gilberto Freyre, a qual, inicialmente encarada com indiferença e até alguma crítica, acabou por merecer uma ampla aceitação nos círculos intelectuais favoráveis ao regime estadonovista de Oliveira Salazar (CASTELO, 1998). Tanto assim que o número de referências a este sociólogo e aos seus livros, em discursos oficiais, em teses académicas e nos contactos epistolares que manteve com a intelligentzia lusa, resulta vasto (CASTELO, 2002).

Mais importante ainda, o luso-tropicalismo, uma vez secundarizado o impacto da miscigenação, serviu de bandeira política ao governo de Lisboa, no momento de combater os "ventos da História" anticoloniais que iam soprando com cada vez maior ímpeto, após 
o fim da Segunda Guerra Mundial, tendendo a apresentar-se um Portugal "uno do Minho a Timor", em que as questões raciais teriam sido ultrapassadas, por se tratar de um colonialismo benigno, diferente dos outros, não racista, fundamentado em princípios cristãos e não imperialistas, obviamente paternalista (ou fraterno, consoante a metáfora familiar escolhida) e apto a cumprir os desígnios civilizadores (ainda que este último conceito, ou antes a palavra, tivesse começado a cair em desuso) (NETO, 2009: 70-71). Eis, em poucas linhas, a visão final desta ideologia secular, que também nutriu a oposição ao Estado Novo, pelo menos até aos anos cinquenta do século passado, quando o Partido Comunista Português (PCP) condenou, de modo inequívoco, o colonialismo, enquanto sistema de exploração do "homem pelo homem" (MADEIRA, 2003).

Partindo, então, da análise desta questão na contemporaneidade e do recente debate havido, o presente artigo propõe-se analisar a questão da ideologia colonial, tomando como ponto de partida dois vultos portugueses da primeira metade do século XX, Augusto de Castro (1883-1971), director do Diário de Notícias e embaixador em várias capitais europeias, e o general Norton de Matos (1867-1955), antigo governador colonial de Angola e mentor da preparação do Corpo Expedicionário Português (CEP), na Primeira Guerra Mundial, os quais militaram a favor e contra o Estado Novo, respectivamente, afinando o seu diapasão por argumentos aparentemente contrários, mas que se encontram próximos na defesa do ideário ultramarino, com referências à obra de Gilberto Freyre e Sérgio Buarque de Holanda. Ademais, ambos mantiveram relações com intelectuais brasileiros e com revistas aí sedeadas. Augusto de Castro escreveu na revista Atlântico (1942-1950), que resultou da edição conjunta do Secretariado Nacional da Propaganda Nacional (SPN) e do Departamento de Imprensa e Propaganda (DIP), ou seja, um veículo ideológico dos dois "Estados Novos", português e brasileiro, enquanto Norton de Matos assinou artigos no Boletim da Sociedade Luso-Africana do Rio de Janeiro (1931-1939), que acolheu oposicionistas (mas também, de igual modo, deu guarida a apoiantes da "Situação" política). Assim, em suma, fazendo uso de diferentes fontes, pretende-se contrastar os escritos de dois autores que escreveram acerca destas temáticas, concatenar o contributo epistemológico freyriano, para equacionar as sobrevivências (e possíveis desenvolvimentos) da problemática no tempo presente. 


\section{Uma (est)ética luso-tropical?}

De entre as muitas fotografias que Alfredo Cunha colheu nos anos que mediaram a transição para a democracia, no rescaldo do 25 de Abril de 1974, uma houve que parece condensar num único e poderoso vislumbre a complexa relação dos portugueses com o seu (ex-)império: junto ao Padrão dos Descobrimentos, orlado por estátuas de navegadores e homens da ciência e da cultura quatrocentista e quinhentista, que foi levantado ao tempo das exposições coloniais do Estado Novo, acumulam-se os caixotes com os pertences despachados pelos antigos colonos, conhecidos como "retornados", quando do seu regresso a Lisboa, no seguimento do processo conducente às independências na "África Portuguesa". Outras obras, como o romance As Naus (ANTUNES, 1988), justapondo, no mesmo tempo histórico, caravelas e cargueiros, naus e batelões, barris de especiarias e malas de viagem, marinheiros do século XV e retornados, numa mordaz crítica de desconstrução à memória empolada do expansionismo marítimo (TORGAL, 2005); como o filme Non ou a Vã Glória de Mandar (1990), de Manoel de Oliveira, entretecendo na narrativa de um oficial da Guerra Colonial os episódios mais dramáticos da história (e da mitologia) lusa, culminando numa (nova) refundação do país, com o 25 de Abril, sob o simbolismo brumoso do regresso de D. Sebastião; como, sob a forma de ensaio, o mencionado Eduardo Lourenço, qualificou de "labirinto da saudade" essa dúbia relação dos portugueses com o (ex-)império. Uma relação tão complexa como o sentimento que o autor escolhia para intitular o seu livro. Uma relação pautada pelo desencontro entre a triunfal mitologia fabricada durante décadas pela propaganda e o aparente desinteresse pelo desmoronar do edifício imperial (LOURENÇO, 2004). Mas, ao mesmo tempo, uma permanente nostalgia do passado quatrocentista e quinhentista, patenteada na toponímia das ruas, ainda saudosa do império, na Exposição Mundial de 1998, em Lisboa, sob o tema genérico dos oceanos, e na cerimónia de abertura do Campeonato Europeu de Futebol de 2004.

Um eloquente veículo de análise desta aparente contradição reside no manual escolar. Definido como "um instrumento pedagógico inseparável das condições e dos métodos de ensino da sua época [pois que] reflecte as tradições, as inovações e até mesmo as utopias pedagógicas do seu tempo" (CHOPIN, 1992: 20), o manual, de igual modo, “esconde a maneira como a historiografia se constrói. Camufla o modo de produção das representações que fornece, a sua relação com os arquivos. Impede o estudante de ver 
como tudo se origina, de ser ele próprio produtor da história e da historiografia" (DUBY, LE GOFF \& LADURIE, 1984: 13). Em especial, esta última conceptualização espelha a tensa dinâmica entre Estado e sociedade, assim como os intervenientes directos em sala de aula, ou seja, docente e discente. Se o ensino obrigatório, gratuito e universal, para lá da utopia iluminista de fazer chegar a razão a todo o género humano, recebeu um impulso maior com a afirmação do Estado-Nação oitocentista, na sua tentativa de formar o cidadão-soldado nos valores patrióticos de defesa do torrão natal, o certo é que a função da escola em muito se alargou. A título de exemplo, note-se que a terminologia "Ministério da Instrução" deu lugar a "Ministério da Educação".

Neste sentido, as mais recentes investigações acerca da visão do Outro, que perpassam os manuais escolares da disciplina de História ${ }^{1}$, escritos de acordo com as metas educativas emanadas da tutela escolar, apontam para uma prevalência do etnocentrismo, da exaltação da "época áurea" dos "Descobrimentos", tendendo a silenciar os males da escravatura e do colonialismo (VIANA, 2011). De resto, o número de páginas consagrado a estas temáticas tem decrescido, ao mesmo tempo que se põe a tónica na aculturação artística, religiosa e gastronómica, como se o "dar novos mundos ao Mundo" continuasse a ser a palavra de ordem. Ou seja, trata-se de um "colonialismo suave", diferente dos outros, que prosseguiria as teses de Gilberto Freyre e, sobretudo, a leitura que o Estado Novo fez das suas ideias, sob um pano de fundo mais antigo de crenças (ARAÚJO \& MAESO, 2016). A perspectiva apresentada é, pois, europeísta e estruturalista, seguindo o esquema hegeliano das "conquistas" civilizacionais, que transitam de Oriente para Ocidente (Suméria, Egipto, Grécia, Roma, Europa Ocidental), abordando-se, por vezes, o caso português.

Diversos factores têm agudizado este estado de coisas. Em primeiro lugar, a acentuada perda de importância das ciências sociais e humanas, traduzido na redução do número de horas semanais da disciplina de História. Por outro lado, persistem estereótipos que, muitas vezes, são percebidos/ou tendem a querer passar como inofensivos junto de um tecido social que rejeita a ideia da existência de racismo. Atente-te no figurino do actual governo, chegado ao poder em finais de 2015, chefiado por um cidadão com

\footnotetext{
${ }^{1}$ Note-se a este propósito que, em Portugal, o sistema educativo encontra-se estruturado em ensino préescolar (até aos seis anos); ensino básico, cindido em três ciclos: $10^{\circ}$ Ciclo (dos seis aos nove anos), 2. ${ }^{\circ}$ Ciclo (dos dez aos onze anos), $3 .^{\circ}$ Ciclo (dos doze aos catorze anos); e Secundário (dos quinze aos dezassete anos). Se bem que, no $1 .{ }^{\circ}$ Ciclo, algumas temáticas históricas sejam abordadas, é apenas no $2{ }^{\circ}$ Ciclo que existe uma disciplina de "História e Geografia de Portugal". O 3. ${ }^{\circ}$ Ciclo integra a disciplina de "História", versando os conteúdos desde a evolução do ser humano até à actualidade. No que concerne ao Secundário, os estudantes poderão ter a disciplina de "História", caso optem pelo curso de "Humanidades".
} 
ligações familiares a Goa, o qual integrou, pela primeira vez, ministros e secretários de Estado oriundos de minorias. Ora, no discurso público, em breve surgiram duas percepções opostas: ou de sublinhar a extracção dos políticos em detrimento das suas virtudes, quase em jeito de apodo, sobressaindo como seu traço identificativo maior aquela (não) pertença; ou de extrapolar dessa excepção todo um entendimento mais lato de como o racismo se teria tornado residual na sociedade portuguesa (PEREIRA, 2015).

Tem sido, outrossim, afirmado por alguns estudiosos destas problemáticas, ultimamente discutidas na imprensa (HENRIQUES \& BATISTA, 2016), com a colaboração de historiadores e outros cientistas sociais, que:

Com a ênfase europeia no multiculturalismo, Portugal volta a apresentar-se como tendo um papel pioneiro, ressuscitando "o discurso lusotropicalista que foi apropriado pelo Estado Novo" - essa ideia de que os portugueses sempre tiveram melhor capacidade de adaptação a outros povos e culturas. Nunca se discute o fenómeno do racismo. Ou é tido como um fenómeno circunscrito a outros, ou como uma atitude individual, ou como ligado a situações extremas, como o nazismo (VIANA, 2011)

A apropriação da doutrina de Gilberto Freyre advém, na realidade, de um lento processo mediador. O Scramble for Africa ou "corrida colonial" por um "lugar ao sol", metáfora do imperialismo colonial oitocentista, foi precedido e acompanhado por sucessivas tentativas de conhecer e catalogar o Outro encontrado nesses territórios. Não deve estranhar tal coincidência. O "mito ariano", que leva o selo desses tempos, veio a entrelaçar-se com o darwinismo social, sendo o famoso Essai sur l'inégalité des races humaines (1853-5), de Arthur de Gobineau, quase exacto contemporâneo do On the origin of species (1859). Por sua vez, a Frenologia e a crescente proliferação de taxonomias dos diferentes grupos humanos potenciaram o desenvolvimento do racismo (POLIAKOV, 1985: 137), tendo-se recuperados os estereótipos - que há muito vingavam - sobre miscigenação e degenerescência. Numa palavra: ciência, pseudociência, mito e tradição deram as mãos, buscando revestir o colonialismo com as cores mais favoráveis.

Em Portugal, sabe-se que a ideologia ultramarina invocava inalienáveis direitos históricos consagrados pelas descobertas quatrocentistas e quinhentistas. De igual modo, reivindicava um especial talento nas relações com o Outro, fruto de muitos séculos de contacto, que compensaria a falta de capital económico e demográfico para ocupar, 
"civilizar" e explorar os territórios d'além-mar. Além da reduzida influência no xadrez político internacional, à qual se juntavam acusações de continuar a manter situações de escravatura encapotada, um terceiro aspecto pesava no menosprezo dispensado pelas outras nações. Consistia na crença de que as sucessivas invasões da Península Ibérica, durante a Antiguidade, por povos africanos e semitas, assim como a miscigenação da gente portuguesa durante o expansionismo marítimo, haviam maculado a pureza do seu suposto sangue ariano.

Ora, vários autores portugueses tenderam a desenvolver estas ideias, mas valorizaram o papel da multiplicidade étnica na construção da identidade nacional. Recordem-se os escritos de alguns membros da Geração de Setenta, como Teófilo Braga e Oliveira Martins, que falavam num (des)encontro entre povos invasores da Península (CATROGA, 1998: 137-185). Ou, duas gerações mais tarde, embora numa outra óptica, o poeta Teixeira de Pascoaes, considerando a idiossincrática saudade enquanto produto do desejo dos povos arianos (gregos, romanos, godos, celtas) e da esperança dos povos semitas (fenícios, judeus e árabes) (PASCOAES, 1998: 56-57).

Em todo o caso, os testemunhos da época esclarecem que a mestiçagem resultante da colonização ultramarina continuava a ser encarada como um subproduto e/ou mal necessário dos séculos anteriores. Os finais de Oitocentos e as primeiras décadas de Novecentos não assinalaram grandes mudanças no que à visão do colonizado respeita. As medidas de assimilação foram sempre tímidas e apenas os habitantes de Cabo Verde, Índia e Macau gozavam da plena cidadania. A escolaridade primava pela incipiência, tardando os estabelecimentos de ensino a chegar ao Ultramar: algumas escolas primárias, poucos liceus, nenhuma universidade. Tratava-se, afinal, de travar o surgimento de elites cultas autóctones, mais aptas a reivindicar direitos de igualdade e até uma hipotética autonomia descentralizadora (ANDRADE, 1997).

Houve mesmo autores que rotularam de desnecessário o ensino ministrado ao colonizado. De modo que, até aos anos cinquenta/sessenta, época em que a pressão internacional para a descolonização começou a fazer valer toda a sua força, acusando Portugal de não desenvolver as colónias, os sucessivos regimes políticos pouco investiram na educação d'além-mar. Ademais, a própria concessão da cidadania a todos os povos colonizados - S. Tomé e Príncipe e Timor (1953) e Guiné, Angola e Moçambique (1961) - não passou de uma operação de cosmética, destinada a convencer a comunidade internacional do suposto carácter benigno e modernizador do colonialismo luso (TORGAL, 2002: 147-165). 
No mesmo sentido deve ser compreendida a aparente mudança de paradigma ideológico: o darwinismo social deu lugar à teoria luso-tropical do sociólogo Gilberto Freyre. Esta tese defendia que o "êxito" da acção colonizadora se ficara a dever ao carácter "plástico" dos portugueses, o qual estimulara a miscigenação étnico-cultural e a sã convivência racial (FREYRE, 1957: 18-29). Inspirando-se nas teorias de povoamento mestiço da Geração de Setenta, nos ensinamentos do antropólogo Franz Boas e em muitos aspectos da colonização brasileira, o luso-tropicalismo foi um esteio do Estado Novo quando da campanha anticolonialista movida a Portugal até às independências em África.

Freyre, que empreendeu uma viagem a Portugal e às suas colónias, em 1951, a convite do governo, interessado em apadrinhar as suas teorias, correspondeu-se com numerosos vultos portugueses: 142 entre os anos de 1922 e 1987 (CASTELO, 2002: 421422). Avultam, entre outros, figuras políticas do regime estadonovista (Marcelo Caetano, Sarmento Rodrigues, o próprio Salazar, José Tenreiro, e José Caeiro da Mata); figuras da oposição (António Sérgio, Nuno Simões); e escritores de variados quadrantes políticoideológicos (José Osório de Oliveira, Maria Archer, Hernâni Cidade, António Quadros, e Natália Correia).

\section{Ensaio de um duplo esboço biográfico}

Augusto de Castro Sampaio Corte-Real foi um advogado, jornalista, político, diplomata e dramaturgo português que, por três, vezes assumiu o cargo de director do mais antigo diário luso ainda em publicação, o Diário de Notícias: de 1919 a 1924, de 1939 a 1945, e de 1947 a 1971 (LEMOS, 2006: 260). Após a venda, em 1919, deste periódico, pela família proprietária à empresa moageira Companhia Industrial de Portugal e Colónias (MATOS, 2010: 11), Augusto de Castro, que fora intermediário no negócio, assumiu a direcção do jornal e, passou a defender abertamente os interesses da companhia proprietária, abrindo-se também aos sectores políticos, económicos e militares que viriam a tomar o poder em 1926, altura a partir da qual o Diário de Notícias foi considerado, entre os diários portugueses de maior tiragem, o que mais fielmente reflectia as orientações governamentais (TORGAL, 2009: 575-576).

Em Fevereiro de 1924 deixou a direcção do matutino lisboeta, para iniciar a sua carreira diplomática por Londres (TEIXEIRA, 2011: 25), mas regressou quinze anos depois, para logo no ano seguinte, em 1940, inaugurar as novas instalações do periódico, 
que saiu do Bairro Alto, da Rua do Diário de Notícias, para as novas instalações na Avenida da Liberdade, um projecto do arquitecto Porfírio Pardal Monteiro, o primeiro feito de raiz para um jornal português.

Licenciado em Direito pela Universidade de Coimbra em 1903, Augusto de Castro começou por exercer advocacia na sua cidade natal, o Porto. Quase em simultâneo, iniciou a actividade de jornalista, assumindo, primeiramente, a direcção de A Província, fundada por Oliveira Martins (MARTINS, 1999: 64), e passando depois para a do vespertino Folha da Noite (1904-1905). Foi ainda redactor-principal do Jornal do Comércio (1907-1909) e cronista de O Século - Edição da Noite, assinando a secção "Palavras leva-as o vento".

Como político iniciou a sua carreira nos anos finais da Monarquia Constitucional, ao ser eleito deputado pelo Partido Progressista. Perfeitamente sintonizado com o regime de António de Oliveira Salazar, foi deputado da Assembleia Nacional nas II, III, VI, VII, VIII, IX e X Legislaturas e ganhou notoriedade como comissário-geral da Exposição do Mundo Português de 1940 (BARROS, 1996: 325).

Enquanto diplomata exerceu funções de embaixador em Londres (1924), no Vaticano (1924-1929), em Bruxelas (1929-1931; 1935-1938), em Roma (1931-1935) e, em Paris (1945-1947), bem como de observador do governo português à Assembleia Geral da ONU (1948) e de representante de Portugal nas conferências sobre o Plano Marshall (1948-1949). Para Augusto de Castro, o exemplo máximo da universalidade e da grandeza europeias era a cidade de Roma, na época do Fascismo e de Mussolini, pelos quais nutria profunda admiração (CASTRO, 1936: 45).

O fascismo, internamente, representou a romanização da Itália: quer dizer, a restituição de Roma ao seu destino construtor e universal. Este foi a consagração duma forma de civilização imperial, nitidamente romana, em que o Oriente e o Ocidente uma vez mais se fundiram num movimento doutrinário de acentuado carácter místico e colectivo (CASTRO, 1936: 37).

Membro da Academia Brasileira de Letras, da Academia Internacional de Cultura Portuguesa e da Academia das Ciências, Augusto de Castro foi também escritor, sobretudo um dramaturgo, destacando-se as suas peças Caminho Perdido (1906), A Culpa (1918) e, as comédias, Amor à Antiga (1907), Chá das Cinco (1909), e As Nossas Amantes (1912), embora também tenha publicado as novelas $O$ Amor e o Tempo (1955), As 
Mulheres e as Cidades (1958) e, os ensaios, Imagens da Europa vistas da minha janela (1936), A Exposição do Mundo Português e a sua Finalidade Nacional (1940), A Crise Internacional e a Política Externa Portuguesa (1949), e Subsídios para a História da Política Externa Portuguesa durante a Guerra (1958).

Quanto ao general José Norton de Matos, natural de Ponte de Lima, no Minho, a sua longa vida (1867-1955) teve na questão colonial, apesar do "Milagre de Tancos" (preparação do CEP para a Guerra de 1914-18) e da sua candidatura à Presidência da República, em 1949, um esteio maior. Com efeito, a sua comissão na Índia (1898-1908), onde dirigiu os serviços de agrimensura, a sua participação na missão encarregue de delimitar os limites de Macau (1909-1910), assim como os cargos de Governador-Geral (1912-1915) e de Alto-Comissário (1921-1924) da província de Angola, assinalaram muitos anos de actividade no Ultramar, a que se seguiu, uma vez concluída a acção no terreno, a redacção de livros de pendor doutrinário e uma vasta colaboração em jornais e revistas, sendo de destacar aquela que desenvolveu n'O Primeiro de Janeiro (1931-1954). De resto, é possível falar num saber sobretudo de experiência feito, passe a expressão, em que Norton beneficiou do contacto directo com colonialistas de gerações anteriores, como Mouzinho de Albuquerque, Henrique Paiva Couceiro ou Joaquim José Machado. Seja como for, as leituras dos clássicos ingleses da colonização tiveram o seu lugar no ideário "nortoniano", expressando o general grande apreço pela aliança com a Grã-Bretanha e alguma admiração pelos seus processos administrativos nos territórios africanos e na Índia.

Foi neste último território, contemplando o passado, que assumiu o seu nacionalismo de pendor imperial:

As fortalezas, com tudo o que de heróico a elas anda ligado; as extensas linhas de muralhas, correndo em ruínas por essa costa do Oceano Índico, revelando esforço e a tenacidade da raça; os templos; as igrejas, as ermidas, essa Goa desparecida, mas tão viva no coração de todos nós [...] transportando para longes terras a pátria distante, impondo as suas leis, a sua língua, as suas crenças, as suas habitações, o vestuário, a alimentação, as mais pequenas particularidades do seu viver, com uma pertinácia e uma dificuldade de se amoldar a hábitos diferentes dos seus [...] numa luta constante com raças com raças que tão diferentes são da sua (MATOS, 1904: I). 
Foi em Angola, olhando para o futuro, que gizou um programa de reformas a empreender:

I. Passagem da organização administrativa militar para a organização administrativa civil. A posse civil do território.

II. O novo indígena: da condição de trabalhador recrutado para a de proprietário e cultivador rural.

III. As estradas.

IV. A proibição do comércio da "pólvora e armas", e do fabrico e venda das bebidas alcoólicas.

V. A assistência aos indígenas. Higiene e melhoria das condições da vida indígena.

VI. A educação e instrução.

A vida de família e o conforto dos europeus. Habitações, transportes, comunicações, segurança e ordem públicas (MATOS, 2005: 115).

Sobre Norton de Matos escreveu Gilberto Freyre: a "sua presença continua viva em Angola. A Angola moderna começou com ele". Ou, ainda mais enfaticamente: "além de administrador, soube ser político e agir politicamente contra os imperialismos europeus" e animou "novas iniciativas e novos arrojos entre os portugueses" (FREYRE, 1955: 96).

\section{Freyre entre Augusto de Castro e Norton de Matos}

Na sequência do acordo político assinado no dia 4 de Setembro de 1941, que tinha por objectivo "promover a colaboração cultural entre os governos de Portugal e do Brasil" (FERRO, 1942: 2), foi lançada, no início do ano seguinte, a Atlântico: Revista LusoBrasileira. Editada, simultaneamente, em Lisboa e no Rio de Janeiro, e publicada entre 1942 e 1950, com um total de dezesseis números, agrupados em três séries, a Atlântico foi fundada e dirigida pelo director do SPN, António Ferro, e pelo responsável do DIP, Lourival Fontes (TORQUATO, 2013: 3).

Esta publicação, “de letras e artes de «liberal critério»” (ROSA, 2016: 267), teve, ainda, como director português António d'Eça de Queiroz (1950) e, no Brasil, contou com a direcção de António Coelho dos Reis, Amílcar Dutra de Menezes, Óscar Fontenelle, Waldemar da Silveira e António Vieira de Mel. 
De entre os seus colaboradores artísticos, destacaram-se as figuras de Abel Manta, Almada Negreiros, António Dacosta, Bernardo Marques, Jorge Barradas, Stuart Carvalhais, Vieira da Silva, Arpad Szenes, Barata Feio, Carlos Botelho, Estrela Faria, Leopoldo de Almeida e Sarah Afonso. Contou ainda com a publicação de textos, de importantes escritores, como Alberto Osório de Castro, António Pedro, Aquilino Ribeiro, Camilo Pessanha, Carlos Drummond de Andrade, Castro Soromenho, Cecília Meireles, Delfim Santos, Jorge de Sena, José Régio, Manuel Fonseca, Orlando Ribeiro, Sophia de Mello Breyner Andresen, Vitorino Nemésio, e Ruy Cinatti, entre outros (TORQUATO, 2013: 3)

No primeiro número, num artigo intitulado "Algumas palavras. Apresentação", António Ferro esclarecia os objectivos da publicação e justificava o facto de esta se chamar Atlântico:

O Atlântico, "lago lusitano", na expressão feliz de Oswaldo Aranha, é também a nossa terra comum, o nosso grande traço de união, a estrada real da nossa glória fraterna, a grande distância que, afinal, nos aproxima... Existe o Brasil, existe Portugal, duas nações livres, independentes, por graça de Deus e dos homens. Qual o nosso objectivo? Qual o nosso programa? Revelar o Portugal novo aos brasileiros. Revelar o novo Brasil aos portugueses. A maior parte dos mal-entendidos, das incompreensões entre os portugueses e os brasileiros tem origem nos erros do velho intercâmbio oficial ou privado, no teimoso comércio de antiguidades (FERRO, 1942: 2).

Também no mesmo número, Lourival Fontes, no artigo "Unidade Espiritual", referiu-se à publicação como um meio para o fortalecimento dos "laços de compreensão e de solidariedade entre o nosso país e Portugal” (FONTES, 1942: 3).

Augusto de Castro foi um dos homens de letras que colaborou, pontualmente, com a revista Atlântico. Logo para o seu número dois, dado a lume em Outubro de 1942, escreveu "Juventude e Esplendor do Brasil", partindo das suas lembranças da baía de Guanabara. Embora grande parte do artigo de Augusto de Castro verse a guerra, cumpre aqui analisar as suas considerações sobre a questão "brasileira", redigidas segundo a visão estadonovista que ia assimilando aos poucos as ideias de Gilberto Freyre, pondo sempre a tónica no contributo europeu: 
Produziu-se o prodígio da assimilação dos contributos inferiores pelo tipo étnico superior, que é o branco. $\mathrm{O}$ sangue branco absorveu e dominou os outros. E formou-se, com o decorrer do tempo, no cadinho incomparável de uma Natureza, que revigora e transforma a própria planta humana, numa raça morena, solidamente individualizada, fisiologicamente bela e apta, raiz e flor do solo (CASTRO, 1942: 195).

$\mathrm{Na}$ verdade, todo o seu discurso eurocentrista, não se furta ao costumado estereótipo dos esplendores exóticos oferecidos pela "mulher tropical": "a raça não é o homem; é a mulher. É pela mulher, pelos seus flancos fecundos, pelo ritmo do seu sangue, que a raça se perpetua. É nas suas entranhas e nas suas veias que ela se cria. A mulher é a urna em que as gerações se afeiçoam, o facho sagrado que as transmite" (CASTRO, 1942: 196). No mesmo intuito, percebe-se uma "noção depreciativa" acerca das "raças" (CARNEIRO, 1995: 150), quando indica que uma "geração fisicamente modelar [...] imagem e síntese do futuro Brasil”, fruto “de quatro séculos de colonização portuguesa”, apenas poderá vingar, caso "a forte influência da Europa, dos milhões de colonos alemães e italianos" se sobreponha à "massa do elemento africano misturado à descendência aborígene" (CASTRO, 1942: 195).

Ao contrário de muitos periódicos afectos à "Situação" política, que defendiam a obra colonial do Estado Novo, a Sociedade Luso-Africana do Rio de Janeiro dirigiu uma voz crítica ao regime de Salazar. Segundo Armando Malheiro da Silva e Heloísa Paulo, esta sociedade, criada a 22 de Maio de 1930, foi, também, a única associação brasileira a constituir um "núcleo de propaganda dos valores morais, sociais e históricos das províncias ultramarinas portuguesas e suas possibilidades económicas e turísticas" (SILVA \& PAULO, 2001: 322). Daí que proclamasse a imperiosidade de uma "cruzada pan-lusitana", promovida por figuras da intelectualidade brasileira e portuguesa, ainda que "sem foguetes, sem bandeiras, nem retratos, nem adulações perigosas", que o mesmo é dizer longe da iniciativa oficial de ambos os lados do Atlântico.

O citado boletim semestral, dado à estampa entre Maio de 1931 e Dezembro de 1938, apesar de incluir artigos de vultos próximos da Ditadura Militar e, posteriormente do Estado Novo - como o futuro director da Exposição Colonial do Porto Henrique Galvão, do colonialista Carlos Selvagem, do antigo sidonista Teófilo Duarte, e do publicista da "mística imperial" Alves de Azevedo - e de incluir fotografias, frases 
destacadas e notícias acerca das realizações dos meios situacionistas, deu amplo destaque a figuras da oposição portuguesa, com realce para Norton de Matos.

Desde o início, Norton de Matos granjeou um grande ascendente junto da sociedade. Era, com efeito, sócio honorário de par com Nuno Simões e, para além de ter assinado diversos artigos no boletim, viu muitas das suas frases inscritas nas páginas da publicação, assim como citações que, amiúde, fazia, caso do verso de Camões, "Glória vã não pretende, nem dinheiro", que abria o volume número quatro. Era amigo de alguns sócios-correspondentes, como Gastão Sousa Dias, o qual representava a cidade de Sá da Bandeira, em Angola, ou de Rodrigo Abreu Lima, que respondia por Viana de Castelo. Três das cinco localidades metropolitanas com sócios-correspondentes (Lisboa, Aveiro, Viana do Castelo, Ponte de Lima, Arcos de Valdevez) pertenciam ao Minho, delimitando um inquestionável círculo de influências locais, dominado pelo general.

De facto, a relação com a Sociedade Luso-africana do Rio de Janeiro permitiu-lhe contactar com as obras de Sérgio Buarque de Holanda e Gilberto Freyre. Norton de Matos, que possuía na sua biblioteca alguns livros do segundo, apesar de os citar e até admirar, de acordo com a ideologia vigente, nunca aceitou um dos seus vectores mais preponderantes: a mestiçagem. Nos anos trinta, os seus artigos de $O$ Primeiro Janeiro repetiram essa ideia. Quer afirmando que os colonos de Angola, que "souberam manter sem cruzamentos inconvenientes e prejudiciais a pureza da raça e hoje representam um importante núcleo de portugueses", quer assinalando "o grave problema dos mestiços" pensamento expresso na máxima: "temos de evitar antes de mais e tanto quanto possível, inconvenientes cruzamentos" (MATOS, 1938: 1).

Apesar de Buarque de Holanda não ter publicado no Boletim da Sociedade Lusoafricana do Rio de Janeiro, Norton clarificava, em artigo d'O Primeiro de Janeiro, posteriormente inserido nas Memórias, que "acabo de ler um precioso livro do escritor brasileiro" (MATOS, 1933: 1), que iria comentar. Interessado pela questão agrária e a "transplantação da cultura europeia para uma zona de clima tropical e subtropical", Norton interrogava-se, ainda que julgando saber de antemão a resposta: "não é esta a obra de Angola"? Porque, os colonos portugueses no Brasil (e em Angola) teriam seguido a "ética da aventura", em lugar da "ética do trabalho", beneficiando de uma enorme plasticidade social, da qual estaria ausente "qualquer orgulho de raça" (IDEM, IBIDEM).

Depois, debatia a problemática da hipotética colonização holandesa do Brasil, aventando Norton que, "também, há tempos em Angola se falou muito neste assunto entre indígenas cultos" (IDEM, IBIDEM). No entanto, se aceitava que os holandeses teriam 
conseguido fazer do Brasil uma colónia mais próspera do que os portugueses, negavalhes o mérito de lograrem criar uma nação, até porque teriam empregado colonos que considerava desadequados a essa obra. De proveniência, sobremaneira, urbana, os povoadores holandeses teriam mantido uma férrea clivagem entre senhores e escravos que Norton, implicitamente, divisava na sociedade boer -, pelo que os portugueses, graças à mencionada plasticidade (mestiçagem?) teriam estabelecido as fundações de uma nação em que o racismo teria reduzida expressão, através da conversão da escravatura numa servidão atenuada.

Se Sérgio Buarque de Holanda ecoaria Gilberto Freyre, as palavras de Norton pareciam inspiradoras do discurso estadonovista dos anos cinquenta, quando este apadrinhou a teoria luso-tropical. Sobretudo, quando o general afirmava, contemplando o paradigma brasileiro, que “o mesmo está acontecendo a Angola, e assim vamos cumprindo a nossa missão histórica". Todavia, não obstante haver avaliado positivamente os argumentos dos dois estudiosos brasileiros, tal como os colonialistas Henrique Galvão e Carlos Selvagem, Norton nunca mudou de opinião no que respeita à mestiçagem, mantendo a crença de que esta, essencial no passado, pelo menos na Índia de Afonso de Albuquerque, e inevitável no futuro, uma vez findo o processo civilizador dos “indígenas", seria inoportuna no presente, em virtude de criar um terceiro elemento entre colonizador e colonizado, susceptível de perturbar a acção do primeiro.

\section{Fontes}

CASTRO, Augusto de (1936). Imagens da Europa: vistas da minha janela. Lisboa: Empresa Nacional de Publicidade.

(1942). Juventude e esplendor do Brasil. Atlântico: Revista Luso-Brasileira. Rio de Janeiro/Lisboa: DIP/SNP/SNI, vol. 1, n. 2, 2 sem., pp. 191-207.

FERRO, António (1942). Algumas palavras de António Ferro. Apresentação. Atlântico: Revista Luso-Brasileira. Rio de Janeiro/Lisboa: DIP/SNP/SNI, vol. 1, n. 1, 1 sem., p. 2.

FONTES, Lourival (1942). Unidade Espiritual. Atlântico: Revista Luso-Brasileira. Rio de Janeiro/Lisboa: DIP/SNP/SNI, vol. 1, n. 1, 1 sem., p. 3.

MATOS, José Norton de (1904). Introducção. O Oriente Portuguez. Revista da Commissão Archeologica da India Portugueza. Nova Goa: Imprensa Nacional, vol. 1, n. 1, jan., p. I.

(1938). Colonização. O Primeiro de Janeiro. Porto, 14 de abr., p. 1. (1938). Raízes do Brasil I. O Primeiro de Janeiro. Porto, 22 de set., p. 1. 


\section{Referências Bibliográficas}

ANDRADE, Mário Pinto de (1997). Origens do Nacionalismo Africano. Continuidade e ruptura nos movimentos unitários emergentes da luta contra a dominação colonial Portuguesa (1911-1961). Lisboa: Publicações Dom Quixote.

ANTUNES, António Lobo (1988). As Naus. Lisboa: Publicações D. Quixote/Círculo de Leitores.

ARAÚJO, Marta \& MAESO, Sílvia Rodríguez (2016). Os contornos do eurocentrismo: raça, história e textos políticos. Coimbra: Edições Almedina/CES.

BARROS, Júlia Leitão de (1996). Exposição do Mundo Português. In: ROSAS, Fernando e BRITO, J. M. Brandão de (Dir.). Dicionário de História do Estado Novo. vol. I. A-L. Lisboa: Círculo de Leitores, pp. 325-327.

CARNEIRO, Maria Luiza Tucci (1995). O antissemitismo na Era Vargas (1930-1945). 2. ed. São Paulo: Editora Brasiliense.

CASTELO, Cláudia (1999). "O Modo Português de Estar no Mundo" - O lusotropicalismo e a ideologia colonial portuguesa (1933-1961). Porto: Edições Afrontamento.

CATROGA, Fernando (1998). História e Ciências Sociais em Oliveira Martins. In: CATROGA, Fernando, MENDES, José Amado \& TORGAL, Luís Reis (Dir.). História da História em Portugal. Lisboa: Temas e Debates, pp. 137-185.

CHOPPIN, Alain (1992). Les manuels scolaires: histoire et actualité, Paris: Hachette.

DUBY, Georges, LE GOFF, Jacques, LADURIE, Le Roy \& outros (Dir.) (1984). A Nova História. Lisboa: Edições 70.

FREYRE, Gilberto (1955). Duas Palavras. Seara nova. Número de homenagem a Norton de Matos. Lisboa, ano XXXIV, p. 96, jul./dez.

FREYRE, Gilberto (1957). Casa Grande e Senzala. Lisboa: Edições Livros do Brasil.

HENRIQUES, Joana Gorjão \& BATISTA, Frederico (2016). Série Racismo e Colonialismo. Público. Lisboa, jan./mar.

LEMOS, Mário Matos e (2006). Jornais diários portugueses do século XX. Um dicionário. Coimbra: Ariadne/CEIS20.

LOURENÇO, Eduardo (1976). Situação africana e consciência nacional. Amadora: Bertrand.

LOURENÇO, Eduardo (2004). O Labirinto da Saudade. Lisboa: Gradiva.

MADEIRA, João (2003). O PCP e a Questão Colonial - dos fins da guerra ao V Congresso (1943-1957). Estudos do Século XX. Coimbra: Minerva, n. 3, pp. 209243.

MARTINS, Guilherme d'Oliveira (1999). Oliveira Martins. Um combate de ideias. Lisboa: Gradiva.

MATOS, Helena (2010). Salazar. A Construção do Mito. 1928-1933. Lisboa: Temas e Debates/Círculo de Leitores.

NETO, Sérgio (2009). Colónia Mártir, Colónia Modelo. Cabo Verde no pensamento ultramarino português (1925-1965). Coimbra: Imprensa da Universidade de Coimbra.

NETO, Sérgio (2016). Do Minho ao Mandovi. Um estudo sobre o pensamento colonial de Norton de Matos. Coimbra: Imprensa da Universidade de Coimbra.

PASCOAIS, Teixeira de Pascoais (1998). A arte de ser português. Lisboa: Assírio \& Alvim.

PEREIRA, José Pacheco (2015). Um monhé, uma preta, um cigano e uma cega. Disponível em <http://www.sabado.pt/opiniao/cronistas/pacheco- 
pereira/detalhe/um-monhe-uma-preta-um-cigano--e-uma-cega>. Acesso em: 29 Ago. 2017.

POLIAKOV, Léon (1985). O Mito Ariano. Ensaio sobre as fontes do racismo e dos nacionalismos. S. Paulo: Editora Perspetiva.

ROLlO, Maria Fernanda (1994). Portugal e o Plano Marshall. Lisboa: Editorial Estampa.

ROSA, Vasco (2016). António Ferro e os artistas. In: António Ferro: 120 Anos. Actas. Lisboa: Fundação António Quadros Edições e Texto Editores, pp. 257-268.

SERRANO, Clara Isabel (2017). Arte de falar e arte de estar calado. Augusto de Castro: jornalismo e diplomacia. Coimbra: Imprensa da Universidade de Coimbra.

SILVA, Armando Malheiro da \& PAULO, Heloísa (2001). Norton de Matos, o Brasil e as raízes do paraíso - A construção da colônia ideal e o ideal colonialista. In: PAULO, Heloísa, RAMOS, Maria Bernardete \& SERPA, Élio. O beijo através do Atlântico: o lugar do Brasil no Panlusitanismo. Chapecó: Argos, pp. 279-326.

TEIXEIRA, Nuno Severiano (2011). A República e a política externa. In: MENESES, Filipe Ribeiro de e OLIVEIRA, Pedro Aires (Coord.). A 1. ${ }^{a}$ República Portuguesa. Diplomacia, Guerra e Império. Lisboa: Tinta da China, pp. 23-33.

TORGAL, Luís Reis (2002). 'Muitas Raças, uma Nação' ou o mito do Portugal multirracial na 'Europa' do Estado Novo'. Estudos do Século XX. Coimbra: Quarteto, n. 2, pp. 147-165.

TORGAL, Luís Reis (2005). De l'Empire atlantique eurafricain au communauté des pays de langue portugaise. Réalité, mythe et utopie. Materiaux pour l'histoire de notre temps. Nanterre, n. 77, pp. 61-67, jan./mar.

TORGAL, Luís Reis (2009). Estados Novos. Estado Novo. Ensaios de História Política e Cultura. Vols. I e II. 2. a ed. Coimbra: Imprensa da Universidade de Coimbra.

TORQUATO, Arthur Luís de Oliveira (2013). Ferro e a Atlântico: a Fomentação da Política Cultural Luso-brasileira em 1941. In: XXVII Simpósio Nacional de História. Conhecimento histórico e diálogo social. Natal - RN. 22 a 26 de Jul., pp. 1 - 10. Disponível em: <http://www.snh2013.anpuh.org/resources/anais /27/1372518903_ARQUIVO_ArtigoANPUHArthur.pdf> Acesso: 30 Ago. 2017.

VIANA, Clara (2011). Manuais de História ainda contam o mundo/a moda do Estado Novo. Disponível em <https://www.publico.pt/2011/03/ 27/portugal/noticia/manuais-de-historia-ainda-contam-o-mundo-a-moda-doestado-novo-1486992>. Acesso em: 29 Ago. 2017.

Artigo recebido em 13 de setembro de 2017.

Aprovado em 31 de outubro de 2017.

DOI: 10.12957/intellectus.2017.31652 